\title{
Nutrition delivery of a model-based ICU glycaemic control system
}

\author{
Kent W. Stewart ${ }^{1 *}$, J. Geoffrey Chase ${ }^{1}$, Christopher G. Pretty ${ }^{1}$ and Geoffrey M. Shaw ${ }^{2}$
}

\begin{abstract}
Background: Hyperglycaemia is commonplace in the adult intensive care unit (ICU), associated with increased morbidity and mortality. Effective glycaemic control (GC) can reduce morbidity and mortality, but has proven difficult. STAR is a proven, effective model-based ICU GC protocol that uniquely maintains normo-glycaemia by changing both insulin and nutrition interventions to maximise nutrition in the context of GC in the $4.4-8.0 \mathrm{mmol} / \mathrm{L}$ range. Hence, the level of nutrition it provides is a time-varying estimate of the patient-specific ability to take up glucose.

Methods: First, the clinical provision of nutrition by STAR in Christchurch Hospital, New Zealand ( $N=221$ Patients) is evaluated versus other ICUs, based on the Cahill et al. survey of 158 ICUs. Second, the inter- and intra- patient variation of nutrition delivery with STAR is analysed. Nutrition rates are in terms of percentage of caloric goal achieved.

Results: Mean nutrition rates clinically achieved by STAR were significantly higher than the mean and best ICU surveyed, for the first 3 days of ICU stay. There was large inter-patient variation in nutrition rates achieved per day, which reduced overtime as patient-specific metabolic state stabilised. Median intra-patient variation was 12.9\%; however, the interquartile range of the mean per-patient nutrition rates achieved was $74.3-98.2 \%$, suggesting patients do not deviate much from their mean patient-specific nutrition rate. Thus, the ability to tolerate glucose intake varies signifcantly between, rather than within, patients.

Conclusions: Overall, STAR's protocol-driven changes in nutrition rate provide higher nutrition rates to hyperglycaemic patients than those of $158 \mathrm{ICU}$ from 20 countries. There is significant inter-patient variability between patients to tolerate and uptake glucose, where intra-patient variability over stay is much lower. Thus, a best nutrition rate is likely patient specific for patients requiring GC. More importantly, these overall outcomes show high nutrition delivery and safe, effective GC are not exclusive and that restricting nutrition for GC does not limit overall nutritional intake compared to other ICUs.
\end{abstract}

Keywords: Glycaemic control, Nutrition delivery, Clinical workload, Intensive care unit, Critical care, Hyperglycaemia, Hypoglycaemia, Model-based, Targeted

\section{Background}

The ICU patient is under considerable physiological stress, resulting in $20-40 \%$ of patients experiencing dysregulation of blood glucose (BG) levels [1] and hyperglycaemia [2, 3], which is associated with increased morbidity and mortality [4-6]. Glycaemic variability due to poor control [7] has also been independently

\footnotetext{
*Correspondence: kent.stewart@pg.canterbury.ac.nz

${ }^{1}$ Department of Mechanical Engineering, Centre for Bio-Engineering, University of Canterbury, Private Bag 4800, Christchurch 8140, New Zealand

Full list of author information is available at the end of the article
}

associated with mortality [7-10]. Effective glycaemic control (GC) can reduce mortality and morbidity [1114], organ failure [15] and cost of care [16, 17]. However, due to inter- and intra- patient variability [18-21], GC has proven difficult, and many protocols have increased hypoglycaemia, also associated with increased mortality [22-25], due to the inability to provide consistent, safe and effective GC [25-31].

The model-based STAR (Stochastic TARgeted) protocol has proven to be safe, consistent and effective [32, 33]. The tablet-based STAR protocol uses a clinically evaluated $[34,35]$ physiological insulin-glucose model $[36,37]$ 
in conjunction with a stochastic model of metabolic variability $[38,39]$, to estimate a patient-specific current metabolic state and its potential future variability [40, 41]. Thus, treatments are selected by forward simulation with a clinically specified desired risk of light hypoglycaemia $(5 \% \mathrm{BG}<4.4 \mathrm{mmol} / \mathrm{L})$ due to these possible future variations. STAR has proven to be safe, effective and replicable across ICUs [32].

Uniquely, STAR maintains normal BG levels by changing both insulin and nutrition interventions [33]. Changing nutrition interventions differentiates STAR from other ICU GC protocols [42], as most only change insulin interventions (e.g. [43-47]). STAR maximises nutrition in the context of GC in the $4.4-8.0 \mathrm{mmol} / \mathrm{L}$ range [33, 40]. Hence, the level of nutrition it provides is a patientspecific, time-varying estimate of the ability to take up glucose and is reduced in the face of significant insulin resistance.

Currently, there is also significant debate over the appropriate amount to feed an ICU patient. Many studies have shown mixed results in reviewing caloric intake, route, and timing and their relation to outcome [48-58]. Cahill et al. [59] surveyed the overall nutrition performance of 158 ICUs, from 20 countries, finding significant variation in nutrition delivery. This study also found an ideal relation to mortality at $85 \%$ of the caloric goal nutrition rate set by the respective ICU [51], based on a model fit to the large collection of retrospective survey data obtained from 158 ICUs in 20 countries. This 'Heyland ideal' value and the best performing unit surveyed are used in this study as a guideline for assessing the clinical performance of STAR nutrition delivery.

This paper first evaluates the clinical provision of nutrition by STAR, to a cohort of hyperglycaemic ICU patients, versus all ICU patients in other ICUs based on the survey results of Cahill et al. [59] to assess if safe, effective GC precludes or limits high nutrition delivery, as well as determining if nutrition restriction to obtain GC limits total nutritional intake. Second, the interand intra- patient variation of nutritional delivery, while maintaining normo-glycaemia, is assessed to evaluate a range of glucose/nutrition tolerance in ICU patients on GC. The main outcomes assess clinically provided nutrition using STAR at the cohort level in an international context and then show a best nutrition rate is likely patient specific, particularly for patients requiring GC.

\section{Methods}

\section{STAR GC protocol}

\section{GC protocol overview}

Starting criteria for STAR is two successive BG measurements over $8.0 \mathrm{mmol} / \mathrm{L}$ within a 4 -h period. After two measurements are taken, integral-based parameter fitting
[60] is used to identify a clinically evaluated model-based insulin sensitivity [34-36]. This value is used with a stochastic model, based on historical data, $[33,38,39,61]$ to find the 5th and 95th percentile potential future insulin sensitivity values. These 5 th and 95th percentile insulin sensitivity values and a potential insulin and nutrition intervention are then used to forward-simulate the likely resulting 5th and 95th percentile BG values for that intervention to find the intervention with $5 \%$ risk of $B G<4.4-$ $4.6 \mathrm{mmol} / \mathrm{L}[33,40]$. Full details can be found in [33].

STAR modifies nutrition rate depending on the bounds of predicted potential behaviour, with a preference to increase insulin before reducing nutrition, and to raise nutrition whenever possible $[33,40]$. STAR modulates this nutrition rate between 30 and $100 \%$ of the caloric goal, with a maximum step change of $\pm 30 \%$ caloric goal per hour [33]. ACCP guidelines are used to determine patient-specific daily caloric goal intake of $25 \mathrm{kcal} / \mathrm{kg} /$ day [62].

Overall, STAR attempts to provide the maximum nutrition rate a patient can tolerate while safely keeping BG in the $4.4-8.0 \mathrm{mmol} / \mathrm{L}$ range. However, insulin saturation limits the impact of insulin to lower BG levels on its own [63-65], requiring nutrition restriction in some patients or time periods. Hence, based on STAR's control predictions, providing excess carbohydrates to a patient above this limit would result in excess BG. Therefore, the nutrition rate achieved by STAR represents a 'STAR ideal' patient-specific nutrition rate that maximises their likelihood of falling within the targeted 4.4-8.0 mmol/L BG band, based on their current ability to tolerate glucose.

\section{Christchurch clinical implementation}

Clinical data from 221 hyperglycaemic ICU patients treated with STAR (2011-2015) [32] in the Christchurch Hospital ICU (mixed medical surgical) were used to assess the performance of its variable nutrition delivery. BG, insulin and nutrition data were collected from STAR tablets and thus only exists when patients are on GC. STAR has proven to provide excellent GC in this cohort spending over $88 \%$ time, per patient, in the targeted $4.4-8.0 \mathrm{mmol} / \mathrm{L}$ range, as shown in Table 1. STAR patients in Christchurch are typically fed enterally with the low carbohydrate Glucerna ${ }^{\text {TM }}$ Select $(74.6$ g/L Carbohydrate, $50 \mathrm{~g} / \mathrm{L}$ Protein, $21.1 \mathrm{~g} / \mathrm{L}$ Fibre, Abbott Labs, Illinois, USA), where carbohydrate concentrations exclude indigestible fibre. Parenteral nutrition (PN) is used occasionally, at clinician discretion, to supplement enteral nutrition. While STAR knows of the PN value, it does not regulate it and will still try to provide $100 \%$ of the caloric goal through enteral nutrition (EN). Thus, enabling the possibility of nutrition delivery over $100 \%$ of goal. Cohort demographics are given in Table 1 . 
Table 1 STAR cohort patient demographics and GC performance statistics

\begin{tabular}{ll}
\hline Patient demographics & \\
Number of patients & 221 \\
Number hours of GC & 21,769 \\
Age & $64.0[54.0-72.0]$ \\
Sex (\% Male) & 66.1 \\
ICU length of stay & $8.4[3.1-15.3]$ \\
Days on GC & $2.2[1.2-3.9]$ \\
Admission to GC start (h) & $17.5[7.3-53.8]$ \\
Operative (\%) & 29.0 \\
APACHE II score & $21.0[16.0-27.0]$ \\
ICU mortality (\%) & 28.0 \\
GC performance statistics & \\
BG mean per patient & $6.66[6.36-7.21]$ \\
BG SD per patient & $1.17[0.85-1.65]$ \\
\% Time in targeted band (4.4-8.0 mmol/L) per & $88.42[77.42-94.44]$ \\
patient & \\
\% Time in targeted band (4.4-8.0 mmol/L) cohort & 83.2 \\
\% Time < 4.4 mmol/L cohort & 1.35 \\
\# Patients < 2.2 mmol/L & 4 \\
Patients fed PN (\%) & 46.8 \\
Mean days on PN & $2.0[1.0-5.8]$ \\
Mean PN per day (\% caloric goal) & $6.4[1.5-14.5]$ \\
\hline
\end{tabular}

Data presented as median [IQR] where appropriate

Patients are not weighed in the Christchurch ICU, so ACCP caloric goal feed is approximated by estimating the patient weight. This estimation first assumes an $80 \mathrm{~kg}$ individual and then modifies this value based on frame size (subjective assessment; small, medium, large), age and sex, using Table 2 and Eq. 1 [66].

$$
A * F * G * 80 * 25=\mathrm{kcal} \text { Goal } / \text { Day }
$$

Equation 1 modifies the goal feed rate of $25 \mathrm{kcal} / \mathrm{kg} / \mathrm{day}$ into a maximum range of $1152-2420 \mathrm{kcal} /$ day. In this cohort, the median interquartile range (IQR) goal feed rate was 1800 [1608-1992] kcal/day. Due to clinical circumstances, such as planned surgery requiring a fasted state, medical imaging, and/or gastric tolerances, a patient's

Table 2 Coefficients used to determine an ICU patients daily caloric goal in Christchurch ICU Hospital

\begin{tabular}{lllll}
\hline Frame size (F) & Small & Medium & & Large \\
\hline \multirow{2}{*}{ Age (A) } & 0.9 & 1.0 & & 1.1 \\
& $\leq 39$ & $40-59$ & $60-79$ & $\geq 80$ \\
Gender (G) & 1.1 & 1.0 & 0.9 & 0.8 \\
& Male & & Female & \\
& 1.0 & & 0.8 & \\
\hline
\end{tabular}

nutrition may be stopped or reduced significantly, for short periods, not reflective of the STAR feeding algorithm. In this analysis, all occurrences of feeding less than $30 \%$ caloric goal are ignored (3,135 h, $14.4 \%$ of the time).

\section{Ethics, consent and permissions}

STAR is the standard of care in Christchurch Hospital, New Zealand; therefore, no consent was required from patients to be placed on the STAR GC protocol. The Upper South Regional Ethics Committee, New Zealand, granted approval for the audit, analysis and publication of the retrospective data.

\section{Analysis \\ Overall clinical performance of current STAR variable nutrition protocol}

The mean cohort caloric goal achieved per day in the ICU by STAR, with hyperglycaemic ICU patients, is calculated and compared to the entire ICU patient cohorts reviewed by Cahill et al. [59]. For STAR, information only exists for periods of $\mathrm{GC}$, which are aligned to the appropriate day of ICU stay so comparisons to Cahill et al. [59] are valid. The percentage of caloric goal achieved represents the total caloric intake (including protein calories) from both EN and PN, in regard to the ACCP caloric goal. This analysis helps answer whether caloric restriction for GC, or safe, effective GC in general, preclude or limit nutrition delivery when compared to that achieved by the entire ICU patient cohort.

\section{Per-patient nutrition delivery}

The distribution per patient (median, IQR, 5th-95th range) of caloric goal achieved per day on STAR is calculated. The per-day distribution is compared to the best performing ICU surveyed in [59] and the 85\% 'Heyland ideal' caloric goal presented in [51] to evaluate the percentage of patients who can tolerate more, or less, nutrition than these results. This comparison delineates the range and distribution of glucose and nutrition tolerance for these medical ICU patients.

The mean and variation of caloric goal achieved over a patient's entire stay is assessed in terms of median IQR between patients and to the overall variation seen per day across the entire cohort. This assesses if the overall variability seen per day is due to variable patients or different patient-specific tolerances of nutritional uptake.

\section{Results}

\section{Overall clinical performance of current STAR variable nutrition protocol}

The percentage caloric goal clinically achieved by STAR, each day in ICU, was compared to the survey results in Cahill et al. [59]. Figure 1 shows mean nutrition delivered 

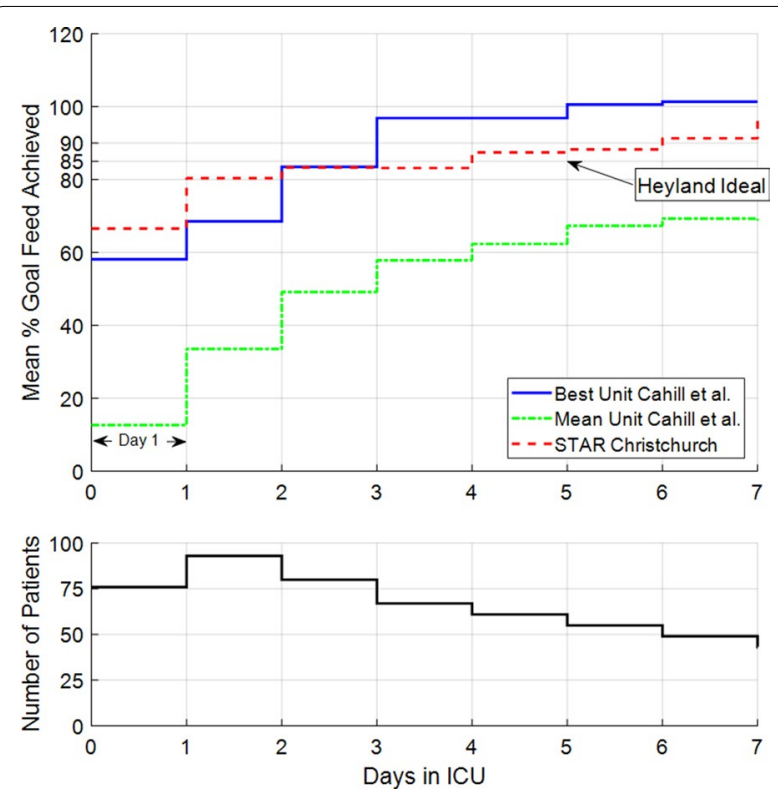

Fig. 1 (Top) Comparison of mean percentage goal feed achieved for each day in the ICU between STAR Christchurch clinical results and the results published in Cahill et al. The 'Heyland ideal' $85 \%$ caloric goal, to minimise mortality, presented in Heyland et al. [51] is also provided for comparison. (Bottom) The number of patients per day, where it is important to note that not all of the 221 patients start on day 1

to hyperglycaemic ICU patients by the variable nutrition protocol in STAR performs very well compared to all ICU patients in the best ICU reviewed in Cahill et al., only slightly underperforming after day 3 . It is well above the mean ICU surveyed on all days, as shown in Table 3. In addition, the mean percentage caloric goal nutrition, per day in ICU, exceeds the 'Heyland ideal' 85\% caloric goal [51] from day 4 onwards.

\section{Per-patient nutrition delivery}

Figure 2 shows the distribution of per-patient mean nutrition rates delivered per day by STAR, including IQR and 5th-95th percentile values. It clearly shows large variation in patient-specific nutrition rates on the first day of ICU stay, which narrows as patient-specific metabolic state stabilises [21]. Table 3 shows over $56.2 \%$ of patients reach or exceed the 'Heyland ideal' $85 \%$ caloric goal in
[51] after day 2, reaching $73.5 \%$ on day 7 . The percentage of patients over the mean ICU result in [59] are also shown in Table 3 to be ranging from $100 \%$ on day 1 to $85.7 \%$ on day 7 . Overall, in comparison with Fig. 1, the per-patient results clearly show some patients cannot achieve this cohort mean rate or the ideal $100 \%$ caloric goal. As noted, the rates in Fig. 2 are an estimate of the 'STAR ideal' time-varying patient-specific nutrition uptake in the context of GC to the 4.4-8.0 mmol/L BG range.

Table 4 shows the median of the mean feed rate achieved over a patient's stay, per patient, is relatively high at $89.8 \%$ caloric goal, but has a large IQR of $23.9 \%$. However, the relatively small median standard deviation of feed rate achieved over a patient's stay, per patient, of $12.9 \%$ shows that individual patients are less variable than the cohort and thus that the overall ability to tolerate glucose is patient specific. Thus, it is clear the ability to take up, and thus to deliver, nutrition varies significantly between GC patients.

\section{Discussion}

Overall clinical performance of current STAR variable nutrition protocol

Figure 1 shows STAR's nutrition protocol, on hyperglycaemic ICU patients, performs equal to or better than the average of all the ICU patients in the best ICU surveyed by Cahill et al. [59] over the first 3 days of ICU stay. After day 3, the best ICU performs slightly better. However, the number of patients on GC is shown to diminish after day 3. This outcome makes the relevance of nutrition performance less significant after this time. Overall, these outcomes show the current STAR nutrition protocol delivers clinical nutrition results for hyperglycaemic patients, which are equal to, or better than, those reported in the Cahill et al. survey for all ICU patients in 158 ICUs in 20 countries. It is clear that high nutritional delivery and safe, effective GC are not mutually exclusive and that variable nutrition to achieve $\mathrm{GC}$ does not reduce total nutritional intake when compared to an entire ICU cohort.

\section{Per-patient nutrition delivery}

Figure 2 shows a large variation in nutrition rates achieved per day, per patient, narrowing and rising as

Table 3 Percentage of patients above the Mean ICU reviewed by Cahill et al. [59] and 'Heyland ideal' rate of 85\% [51]

\begin{tabular}{|c|c|c|c|c|c|c|c|}
\hline Day in ICU & Day 1 & Day 2 & Day 3 & Day 4 & Day 5 & Day 6 & Day 7 \\
\hline $\begin{array}{l}\% \text { Patients > } \\
\text { Mean Unit Cahill et al. }\end{array}$ & 100.0 & 96.8 & 92.5 & 86.6 & 85.3 & 90.9 & 85.7 \\
\hline $\begin{array}{l}\% \text { Patients > } \\
\text { 'Heyland ideal' (85\%). }\end{array}$ & 25.0 & 41.9 & 56.2 & 58.2 & 63.9 & 60.0 & 73.5 \\
\hline
\end{tabular}



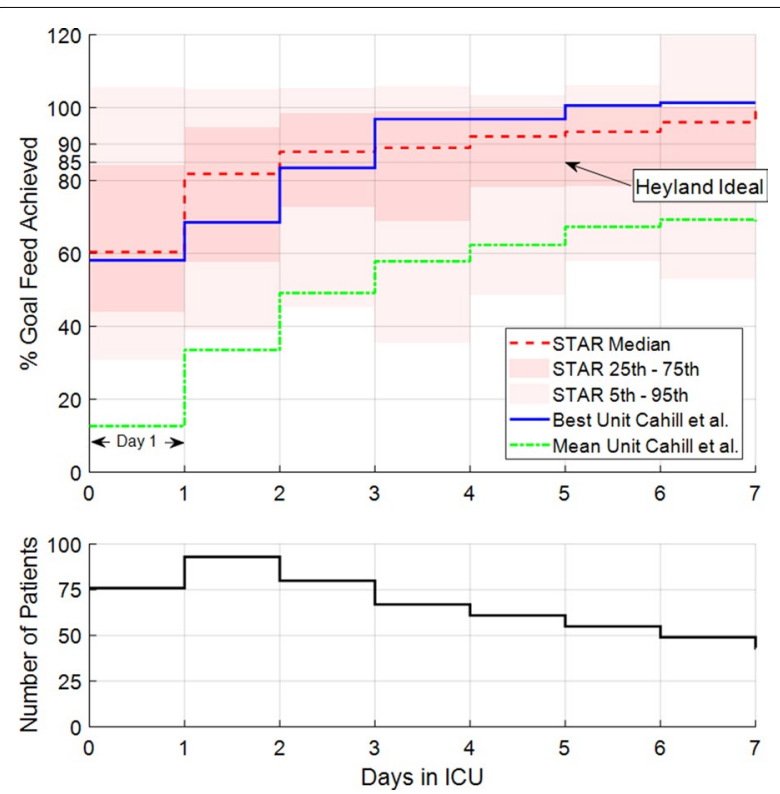

Fig. 2 (Top) Comparison of the median interquartile range of STAR Christchurch's percentage goal feed achieved clinically $(N=221$ Patients) and the best performing unit reviewed in Cahill et al. The 'Heyland ideal' $85 \%$ caloric goal, to minimise mortality, presented in Heyland et al. [51] is also provided for comparison. (Bottom) The number of patients per day, where it is important to note that not all of the 221 patients start on day 1

the patient-specific metabolic state stabilises [21], similar to that seen in Heyland et al. [67]. However, the median variation per patient was only 12.9 [4.6-20.4] \% (Table 4), suggesting patients do not deviate significantly from their mean nutrition rate. This result and the large IQR of the mean feed rates achieved (74.3-98.2\%, Table 4) suggest the lower nutritional delivery to the 5 th and 25 th percentile are a result of a few patients who had a lower ability to tolerate glucose intake.

It is very uncommon for patients not on GC in Christchurch ICU to have their feed rates changed due to the strong clinical culture of patients achieving their caloric goal. In addition, prior to STAR's predecessor, SPRINT, being implemented (2005) [14], feed rates were fixed at $100 \%$ caloric goal during GC for all patients. Hence, if they are not on GC, they are likely to have a fixed $100 \%$ caloric goal nutrition rate and have a BG within 4.4$8.0 \mathrm{mmol} / \mathrm{L}$, having a relatively constant glucose tolerance

\section{Table 4 Per-patient feed rate characteristics}

\begin{tabular}{ll}
\hline Number of patients & $\mathbf{2 2 1}$ \\
\hline $\begin{array}{l}\text { Mean of a patient's feed rate over entire stay, per } \\
\text { patient (\%) }\end{array}$ & 89.8 [74.3-98.2] \\
$\begin{array}{l}\text { SD of a patient's feed rate over entire stay, per patient } \\
\text { (\%) }\end{array}$ & $12.9[4.6-20.4]$
\end{tabular}

Data presented as median [IQR] where appropriate and reduced insulin sensitivity variability $[21,68]$. Therefore, if all patient data were considered, the intra-patient variability seen in Table 4 would likely go down.

Considering STAR feeds the maximum possible nutrition, while safely maintaining normo-glycaemia, the nutrition rates achieved give a good indication of the patient-specific ability to tolerate glucose and thus of their 'STAR ideal' nutrition rate. In essence, every patient is fed the maximum they can achieve with added insulin, within the bounds of the future predicted variability. Therefore, the spread of nutrition rates per patient in the results infer this 'STAR ideal' nutrition rate is very patient specific and evolves with time.

The 'STAR ideal' nutrition rate achieved by STAR was less than the $100 \%$ caloric goal for more than $50 \%$ of patients, over all days. However, the best unit surveyed in Cahill et al. [59] was still considerably lower than this predetermined caloric goal suggesting these generalised approximations do not represent all ICU patients well, as seen in the results for STAR in Christchurch. In addition, over $56 \%$ of patients exceeded the lower $85 \%$ 'Heyland ideal' of [51] by day 3 , as shown in Table 3 .

\section{Limitations}

Cahill et al. [59] provides the percentage caloric goal nutrition achieved by each ICU. However, caloric goals may vary across ICUs. Additionally, the estimation of patient body weight in Christchurch ICU [69], as shown in Table 2, may also bias the caloric goal feed estimate which outlines the need for patients to be weighed on the day of ICU admission in Christchurch Hospital. As a result, some ICUs may thus achieve caloric goal nutrition targets 'more easily' than others, making comparison difficult. However, the $25 \mathrm{kcal} / \mathrm{kg} /$ day ACCP guideline [62] used in the Christchurch ICU, or a similar value guideline $(25-30 \mathrm{kcal} / \mathrm{kg} /$ day SCCM/ASPEN [70], and $20-25 \mathrm{kcal} / \mathrm{kgBW} /$ day initial phase and recovery phase $25-30 \mathrm{kcal} / \mathrm{kgBW} /$ day ESPEN [71]), is commonly used and these cover the range used with STAR patients.

In addition, Cahill et al. review nutrition achieved during the first day of ICU stay, which is not necessarily when GC starts for all patients. Although GC commonly starts at the beginning of ICU stay, it may not always be the case. However, as an ICU patient is under the most amount of stress immediately post-surgery or insult [72], they are most likely to require GC at or near the beginning of their ICU stay [13]. In this study, $59.3 \%$ of patients started GC within $24 \mathrm{~h}$ of being admitted to the ICU (Median $15.5 \mathrm{~h}$, Table 1).

Moreover, Cahill et al. survey the nutrition given to all ICU patients. However, this study only considered patients who required GC. The $25-35 \%$ of patients who require GC in the ICU [28] are the most metabolically stressed and, as a result, have a reduced glucose uptake capacity. They 
are thus often harder to deliver the target nutrition rates $[20,52,57,58]$. In addition, given that 158 ICUs over 20 countries were surveyed by Cahill et al. [59], and this ICU was 1 of the 22 surveyed in Australia, and New Zealand the mixed medical surgical ICU in Christchurch Hospital would likely have patients with similar parameters. Therefore, achieving nutrition rates with high performance GC similar to that achieved for all ICU patients, normoglycaemic and hyperglycaemic, in the best ICU reviewed by Cahill et al. [59] is a significant outcome. More importantly, this outcome and the inter-patient variability in the results indicate high nutrition delivery and safe, effective $\mathrm{GC}$ are not exclusive, an equally, that nutrition restriction to obtain GC does not necessarily reduce total nutrition in an international context.

The insulin-glucose model used by STAR has been shown to be effective in predicting a patient's response [35, $36,73]$. However, as STAR doses based on the 5th and 95th percentile future metabolic variability [38], ensuring only a $5 \%$ risk of hypoglycaemia [74], the majority of patient's future BG will fall within the targeted band. Hence, many patients could possibly remain within the targeted BG range $(4.4-8.0 \mathrm{mmol} / \mathrm{L})$ if given a higher than recommended nutrition rate. As a result, some patients may be able to receive higher nutrition rates than reported here and still be able to be provided effective GC. However, this choice would also increase the likelihood of hyperglycaemia, reducing the safety of GC provided by STAR.

The $85 \%$ caloric goal presented in Heyland et al. is calculated by a model fit to retrospective data from 158 ICUs and clinical practices, and while it represents a significant body of multi-centre data, it may not be causative. Many prospective trials have found improved outcomes for even lower hypo-caloric feeding [50, 75-77]. Therefore, this 'Heyland ideal' value may overestimate the caloric goal required for improved outcomes and may be reflective of 'less sick' patients tolerating higher nutrition. This study is designed to show that STAR can provide high nutrition rates while still providing safe and effective GC. In addition, STAR is designed to be flexible to different nutrition goals while still providing effective GC.

Other factors, such as mechanical ventilation, neurologic injury, gastric emptying and paresis patients, are well known to influence the nutritional requirements of ICU patients. This is another strong limitation of this retrospective analysis, as this detailed information was not available. However, the cohort was typical of medical ICU in Christchurch.

The STAR GC protocol uses model-based patientspecific control in conjunction with a stochastic model to predict the best treatment for a patient. As shown in Table 1 and [32], STAR is able to achieve very good GC with a compliance of over $96.8 \%$ in all interventions and near identical results across multiple ICUs [32]. However, in many clinical practices, the idea of protocoldriven changes in the nutrition given to a patient for GC is foreign and thus clinically unacceptable. Thus, the main focus of this study is to show that protocol-driven changes in nutrition rate do not preclude in achieving better nutrition delivery rates than those of 158 ICUs from 20 countries. In addition, the concept of nutritional tolerances in relation to glucose tolerances provides a potentially new method of calculating patient-specific feed rates and should be investigated further in future studies.

\section{Conclusions}

The STAR GC protocol clinical provision of nutrition to hyperglycaemic patients was compared to nutrition rates of entire ICU cohorts surveyed in 158 ICUs in Cahill et al. [59]. Mean nutrition rates clinically achieved by the STAR variable nutrition protocol were significantly higher than the mean and best ICU surveyed, for the first 3 days of ICU stay. Overall, STAR's protocol-driven changes in nutrition rate provide on average nutrition rates for hyperglycaemic patients which are equal to, or better than the mean of all ICU patients in 158 ICUs from 20 countries. More importantly, these outcomes show high nutrition delivery and safe, effective GC are not exclusive and that restricting nutrition for GC does not limit overall nutritional intake compared to other ICUs.

The inter- and intra- patient variation of nutritional delivery was assessed in the STAR cohort There was large inter-patient variation in nutrition rates achieved per day, which reduced overtime as patient-specific metabolic state stabilised. Median intra-patient variation was $12.9 \%$; however, the IQR of the mean per-patient nutrition rates achieved was $74.3-98.2 \%$, suggesting patients do not deviate much from their mean patient-specific nutrition rate and thus that the ability to tolerate glucose intake varies significantly between, rather than within, patients. There is significant inter-patient variability between patients to tolerate and uptake glucose, where intra-patient variability over stay is much lower. Thus, a best nutrition rate is likely patient specific for patients requiring $\mathrm{GC}$.

\section{Abbreviations}

STAR: stochastic TARgeted; GC: glycaemic control; BG: blood glucose; IQR: interquartile range; ICU: intensive care unit; ACCP: American College of Chest Physicians; PN: parenteral nutrition.

\section{Author's contributions}

JGC, GS and CP conceived and developed the STAR protocol. GS assisted implementing the protocol in the Christchurch ICU, New Zealand. KS assisted in the data collection. KS undertook all of the analysis, interpretation of the clinical data. KS, CP and JGC drafted the manuscript. All authors approved the final manuscript. 


\section{Author details}

${ }^{1}$ Department of Mechanical Engineering, Centre for Bio-Engineering, University of Canterbury, Private Bag 4800, Christchurch 8140, New Zealand. ${ }^{2}$ Department of Intensive Care, Christchurch Hospital, Christchurch, New Zealand.

\section{Acknowledgements}

None.

\section{Competing interests}

The authors declare that they have no competing interests.

\section{Availability of data and materials}

The datasets used and/or analysed during the current study are available from the corresponding author on reasonable request.

\section{Consent for publication}

Not applicable.

\section{Ethics approval and consent to participate}

STAR is the standard of care in Christchurch Hospital, New Zealand; therefore, no consent was required from patients to be placed on the STAR GC protocol. The Upper South Regional Ethics Committee, New Zealand, granted approval for the audit, analysis and publication of the retrospective data.

\section{Funding}

We acknowledge the support of UC Doctoral Scholarships for Kent Stewart, as well as funding from EU FP7, RSNZ IRSES mobility grants and the HRC of NZ.

\section{Publisher's Note}

Springer Nature remains neutral with regard to jurisdictional claims in published maps and institutional affiliations.

Received: 19 October 2017 Accepted: 29 December 2017 Published online: 10 January 2018

\section{References}

1. Clutter WE, Bier DM, Shah SD, Cryer PE. Epinephrine plasma metabolic clearance rates and physiologic thresholds for metabolic and hemodynamic actions in man. J Clin Investig. 1980;66:94-101.

2. McCowen KC, Malhotra A, Bistrian BR. Stress-induced hyperglycemia. Crit Care Clin. 2001;17:107-24

3. Shamoon H, Hendler R, Sherwin RS. Synergistic interactions among antiinsulin hormones in the pathogenesis of stress hyperglycemia in humans. J Clin Endocrinol Metab. 1981:52:1235-41.

4. Capes SE, Hunt D, Malmberg K, Gerstein HC. Stress hyperglycaemia and increased risk of death after myocardial infarction in patients with and without diabetes: a systematic overview. Lancet. 2000;355:773-8.

5. Krinsley JS. Association between hyperglycemia and increased hospital mortality in a heterogeneous population of critically ill patients. Mayo Clin Proc. 2003;78:1471-8.

6. Mizock BA. Alterations in fuel metabolism in critical illness: hyperglycaemia. Best Pract Res Clin Endocrinol Metab. 2001;15:533-51.

7. Uyttendaele V, Dickson JL, Shaw GM, Desaive T, Chase JG. Untangling glycaemia and mortality in critical care. Crit Care. 2017;21:152

8. Egi M, Bellomo R, Stachowski E, French CJ, Hart G. Variability of blood glucose concentration and short-term mortality in critically ill patients. Anesthesiology. 2006;105:244-52.

9. Krinsley JS. Glycemic variability: a strong independent predictor of mortality in critically ill patients. Crit Care Med. 2008;36:3008-13.

10. Lanspa MJ, Dickerson J, Morris AH, Orme JF, Holmen J, Hirshberg EL. Coefficient of glucose variation is independently associated with mortality in critically ill patients receiving intravenous insulin. Crit Care. 2014;18:R86.

11. Finney SJ, Zekveld C, Elia A, Evans TW. Glucose control and mortality in critically ill patients. JAMA. 2003;290:2041-7.

12. Van den Berghe $G$, Wouters $P$, Weekers F, Verwaest $C$, Bruyninckx F, Schetz $\mathrm{M}$, et al. Intensive insulin therapy in the critically ill patients. N Engl J Med. 2001;345:1359-67.
13. Krinsley JS. Effect of an intensive glucose management protocol on the mortality of critically ill adult patients. Mayo Clin Proc. 2004;79:992-1000.

14. Chase JG, Shaw G, Le Compte A, Lonergan T, Willacy M, Wong XW, et al. Implementation and evaluation of the SPRINT protocol for tight glycaemic control in critically ill patients: a clinical practice change. Crit Care. 2008;12:R49.

15. Chase JG, Pretty CG, Pfeifer L, Shaw GM, Preiser JC, Le Compte AJ, et al. Organ failure and tight glycemic control in the SPRINT study. Crit Care. 2010;14:R154.

16. Krinsley JS, Jones RL. Cost analysis of intensive glycemic control in critically ill adult patients. Chest. 2006;129:644-50.

17. Van den Berghe G, Wouters PJ, Kesteloot K, Hilleman DE. Analysis of healthcare resource utilization with intensive insulin therapy in critically ill patients. Crit Care Med. 2006;34:612-6.

18. Dickson JL, Gunn CA, Chase JG. Humans are horribly variable. Int J Clin Med Imaging. 2014; 1

19. Chase JG, Le Compte AJ, Suhaimi F, Shaw GM, Lynn A, Lin J, et al. Tight glycemic control in critical care - the leading role of insulin sensitivity and patient variability: a review and model-based analysis. Comput Methods Programs Biomed. Elsevier Ireland Ltd; 2011;102:156-71.

20. Suhaimi F, Le Compte A, Preiser JC, Shaw GM, Massion P, Radermecker $\mathrm{R}$, et al. What makes tight glycemic control (TGC) Tight? The impact of variability and nutrition in 2 clinical studies. J Diabetes Sci Technol. 2010;4:284-98

21. Pretty CG, Le Compte AJ, Chase JG, Shaw GM, Preiser JC, Penning S, et al. Variability of insulin sensitivity during the first 4 days of critical illness: implications for tight glycemic control. Ann Intensive Care. 2012;2:17.

22. Egi M, Bellomo R, Stachowski E, French CJ, Hart GK, Taori G, et al. Hypoglycemia and outcome in critically ill patients. Mayo Clin Proc. 2010;85:217-24

23. Bagshaw SM, Bellomo R, Jacka MJ, Egi M, Hart GK, George C. The impact of early hypoglycemia and blood glucose variability on outcome in critical illness. Crit Care. 2009:13:R91.

24. Finfer S, Liu B, Chittock DR, Norton R, Myburgh JA, McArthur C, et al. Hypoglycemia and risk of death in critically ill patients. N Engl J Med. 2012:367:1108-18.

25. Griesdale DEG, de Souza RJ, van Dam RM, Heyland DK, Cook DJ, Malhotra A, et al. Intensive insulin therapy and mortality among critically ill patients: a meta-analysis including NICE-SUGAR study data. Can Med Assoc J. 2009:180:821-7.

26. Finfer S, Delaney A. Tight glycemic control in critically ill adults. JAMA. 2008:300:963-5.

27. Brunkhorst FM, Engel C, Bloos F, Meier-Hellmann A, Ragaller M, Weiler N, et al. Intensive insulin therapy and pentastarch resuscitation in severe sepsis. N Engl J Med. 2008;358:125-39.

28. Treggiari MM, Karir V, Yanez ND, Weiss NS, Daniel S, Deem SA. Intensive insulin therapy and mortality in critically ill patients. Crit Care. 2008;12:R29.

29. Kalfon P, Giraudeau B, Ichai C, Guerrini A, Brechot N, Cinotti R, et al. Tight computerized versus conventional glucose control in the ICU: a randomized controlled trial. Intensive Care Med. 2014:40:171-81.

30. Hamimy W, Khedr H, Rushdi T, Zaghloul A, Hosni M, Aal AA. Application of conventional blood glucose control strategy in surgical ICU in developing countries: is it beneficial? Egypt J Anaesth. 2015;32:123-9.

31. Van den Berghe G, Wilmer A, Hermans G, Meersseman W, Wouters PJ, Milants I, et al. Intensive insulin therapy in the medical ICU. N Engl J Med. 2006:354:449-61.

32. Stewart KW, Pretty CG, Tomlinson H, Thomas FL, Homlok J, Noémi SN, et al. Safety, efficacy and clinical generalization of the STAR protocol: a retrospective analysis. Ann Intensive Care. 2016;6:24.

33. Fisk L, Lecompte A, Penning S, Desaive T, Shaw G, Chase G. STAR development and protocol comparison. IEEE Trans Biomed Eng. 2012;59:3357-64.

34. Dickson JL, Stewart KW, Pretty CG, Flechet M, Desaive T, Penning S, et al. Generalisability of a virtual trials method for glycaemic control in intensive care. IEEE Trans Biomed Eng. 2017;1-1.

35. Chase JG, Suhaimi F, Penning S, Preiser JC, Le Compte AJ, Lin J, et al. Validation of a model-based virtual trials method for tight glycemic control in intensive care. Biomed Eng Online. 2010;9:84.

36. Lin J, Razak NN, Pretty CG, Le Compte A, Docherty P, Parente JD, et al. A physiological Intensive Control Insulin-Nutrition-Glucose (ICING) model 
validated in critically ill patients. Comput Methods Programs Biomed. 2011;102:192-205.

37. Stewart KW, Pretty CG, Tomlinson H, Fisk L, Shaw GM, Chase JG. Stochastic Model Predictive (STOMP) glycaemic control for the intensive care unit: development and virtual trial validation. Biomed Signal Process Control. 2015;16:61-7

38. Lin J, Lee D, Chase JG, Shaw GM, Hann CE, LotzT, et al. Stochastic modelling of insulin sensitivity variability in critical care. Biomed Signal Process Control. 2006;1:229-42.

39. Lin J, Lee D, Chase JG, Shaw GM, Le Compte A, Lotz T, et al. Stochastic modelling of insulin sensitivity and adaptive glycemic control for critical care. Comput Methods Programs Biomed. 2008:89:141-52.

40. Evans A, Le Compte A, Tan CS, Ward L, Steel J, Pretty CG, et al. Stochastic targeted (STAR) glycemic control: design, safety, and performance. J Diabetes Sci Technol. 2012;6:102-15.

41. Evans A, Shaw GM, Le Compte A, Tan CS, Ward L, Steel J, et al. Pilot proof of concept clinical trials of Stochastic Targeted (STAR) glycemic control. Ann Intensive Care. 2011;1:38.

42. Kalfon P, Preiser JC. Tight glucose control: should we move from intensive insulin therapy alone to modulation of insulin and nutritional inputs? Crit Care. 2008;12:156.

43. Amrein $\mathrm{K}$, Ellmerer $\mathrm{M}$, Hovorka R, Kachel $\mathrm{N}$, Fries H, von Lewinski D, et al. Efficacy and safety of glucose control with Space GlucoseControl in the medical intensive care unit: an open clinical investigation. Diabetes Technol Ther. 2012;14:690-5.

44. Van Herpe T, Mesotten D, Wouters PJ, Herbots J, Voets E, Buyens J, et al. LOGIC-insulin algorithm-guided versus nurse-directed blood glucose control during critical illness: the LOGIC-1 single-center, randomized, controlled clinical trial. Diabetes Care. 2013;36:188-94.

45. Pachler C, Plank J, Weinhandl H, Chassin LJ, Wilinska ME, Kulnik R, et al. Tight glycaemic control by an automated algorithm with time-variant sampling in medical ICU patients. Intensive Care Med. 2008;34:1224-30.

46. Finfer S, Chittock DR, Su SY-S, Blair D, Foster D, Dhingra V, et al. Intensive versus conventional glucose control in critically ill patients. N Engl J Med. 2009;360:1283-97.

47. Preiser JC, Devos P, Ruiz-Santana S, Melot C, Annane D, Groeneveld J, et al. A prospective randomised multi-centre controlled trial on tight glucose control by intensive insulin therapy in adult intensive care units: the Glucontrol study. Intensive Care Med. 2009;35:1738-48.

48. Doig GS, Simpson F, Finfer S, Delaney A, Davies AR, Mitchell I, et al. Effect of evidence-based feeding guidelines on mortality of critically ill adults: a cluster randomized controlled trial. JAMA. 2008;300:2731-41.

49. Villet S, Chiolero RL, Bollmann MD, Revelly JP, Cayeux RNM, Delarue J, et al. Negative impact of hypocaloric feeding and energy balance on clinical outcome in ICU patients. Clin Nutr. 2005;24:502-9.

50. Krishnan JA, Parce PB, Martinez A, Diette GB, Brower RG. Caloric intake in medical ICU patients: consistency of care with guidelines and relationship to clinical outcomes. Chest. 2003;124:297-305.

51. Heyland DK, Cahill N, Day AG. Optimal amount of calories for critically ill patients: depends on how you slice the cake! Crit Care Med. 2011;39:1.

52. Arabi YM, Aldawood AS, Haddad SH, Al-Dorzi HM, Tamim HM, Jones G, et al. Permissive underfeeding or standard enteral feeding in critically ill adults. N Engl J Med. 2015;372:2398-408.

53. Preiser J-C, van Zanten AR, Berger MM, Biolo G, Casaer MP, Doig GS, et al. Metabolic and nutritional support of critically ill patients: consensus and controversies. Crit Care. 2015;19:1-11.

54. Rice TW. Gluttony in the intensive care unit. Am J Respir Crit Care Med. 2013;187:223-4

55. Weijs PJM, Stapel SN, de Groot SDW, Driessen RH, de Jong E, Girbes ARJ, et al. Optimal protein and energy nutrition decreases mortality in mechanically ventilated, critically ill patients: a prospective observational cohort study. JPEN J Parenter Enteral Nutr. 2012;36:60-8.

56. Singer P, Anbar R, Cohen J, Shapiro H, Shalita-Chesner M, Lev S, et al. The tight calorie control study (TICACOS): a prospective, randomized, controlled pilot study of nutritional support in critically ill patients. Intensive Care Med. 2011:37:601-9.
57. Casaer MP, Mesotten D, Hermans G, Wouters PJ, Schetz M, Meyfroidt G, et al. Early versus late parenteral nutrition in critically ill adults. N Engl J Med. 2011.

58. Rice TW, Wheeler AP, Thompson BT, Steingrub J, Hite RD, Moss M, et al. Initial trophic vs full enteral feeding in patients with acute lung injury: the EDEN randomized trial. JAMA. 2012;307:795-803.

59. Cahill NE, Dhaliwal R, Day AG, Jiang $X$, Heyland DK. Nutrition therapy in the critical care setting: what is "best achievable" practice? An international multicenter observational study*. Crit Care Med. 2010;38:395-401.

60. Hann CE, Chase JG, Lin J, Lotz T, Doran CV, Shaw GM. Integral-based parameter identification for long-term dynamic verification of a glucose-insulin system model. Comput Methods Programs Biomed. 2005;77:259-70.

61. Haidar A, Elleri D, Allen JM, Harris J, Kumareswaran K, Nodale M, et al. Validity of triple- and dual-tracer techniques to estimate glucose appearance. AJP Endocrinol Metab. 2012;302:E1493-501.

62. Cerra FB, Benitez MR, Blackburn GL, Irwin RS, Jeejeebhoy K, Katz DP, et al. Applied nutrition in ICU patients: a consensus statement of the American College of Chest Physicians. Chest. 1997;111:769-78.

63. Fugleberg S, Kolendorf K, Thorsteinsson B, Bliddal H, Lund B, Bojsen F. The relationship between plasma concentration and plasma disappearance rate of immunoreactive insulin in normal subjects. Diabetologia. 1982;22:437-40.

64. Thorsteinsson B. Kinetic models for insulin disappearance from plasma in man. Dan Med Bull. 1990;37:143-53.

65. Natali A, Gastaldelli A, Camastra S, Sironi AM, Toschi E, Masoni A, et al. Dose-response characteristics of insulin action on glucose metabolism: a non-steady-state approach. Am J Physiol Endocrinol Metab. 2000;278:E794-801

66. Chase JG, Shaw GM, Lotz T, LeCompte A, Wong J, Lin J, et al. Model-based insulin and nutrition administration for tight glycaemic control in critical care. Curr Drug Deliv. 2007:4:283-96.

67. Heyland DK, Schroter-Noppe D, Drover JW, Jain M, Keefe L, Dhaliwal R, et al. Nutrition support in the critical care setting: current practice in canadian ICUs_opportunities for improvement? JPEN J Parenter Enteral Nutr. 2003;27:74-83.

68. Thomas F, Pretty CG, Fisk L, Shaw GM, Chase JG, Desaive T. Reducing the impact of insulin sensitivity variability on glycaemic outcomes using separate stochastic models within the STAR glycaemic protocol. Biomed Eng Online. 2014;13:43.

69. Chase JG, Shaw GM, Lotz T, LeCompte A, Wong J, Lin J, et al. Model-based insulin and nutrition administration for tight glycaemic control in critical care. Curr Drug Deliv. 2007:4:283-96.

70. Taylor BE, McClave SA, Martindale RG, Warren MM, Johnson DR, Braunschweig C, et al. Guidelines for the provision and assessment of nutrition support therapy in the adult critically ill patient. Crit Care Med. 2016:44:390-438

71. Kreymann KG, Berger MM, Deutz NEP, Hiesmayr M, Jolliet P, Kazandjiev $G$, et al. ESPEN guidelines on enteral nutrition: intensive care. Clin Nutr. 2006;25:210-23.

72. Cuthbertson DP. Post-shock metabolic response. Lancet. 1942;239:433-7.

73. Stewart KW, Chase JG, Dickson J, Pretty C, Shaw G. Can we fix it? Yes we can! Simplifying nutrition in STAR Glycemic Control. 16th annual diabetes technology meet. 2016.

74. Fisk LM, Le Compte AJ, Shaw GM, Penning S, Desaive T, Chase JG. STAR development and protocol comparison. IEEE Trans Biomed Eng. 2012;59:3357-64.

75. Patino JF, de Pimiento SE, Vergara A, Savino P, Rodriguez M, Escallon J. Hypocaloric support in the critically ill. World J Surg. 1999;23:553-9.

76. Dickerson RN, Boschert KJ, Kudsk KA, Brown RO. Hypocaloric enteral tube feeding in critically ill obese patients. Nutrition. 2002;18:241-6.

77. Arabi YM, Tamim HM, Dhar GS, Al-Dawood A, Al-Sultan M, Sakkijha MH, et al. Permissive underfeeding and intensive insulin therapy in critically ill patients: a randomized controlled trial. Am J Clin Nutr. 2011;93:569-77. 